BMJ Open

Diabetes

Research

\& Care

\section{Maternal diabetes and the risk of feeding and eating disorders in offspring: a national population-based cohort study}

\author{
Hui Wang, ${ }^{1}$ Hua He, ${ }^{1,2}$ Yongfu $\mathrm{Yu}^{3}$ Xiujuan Su, ${ }^{4}$ Fei Li, ${ }^{1,2}$ Jiong Li (D) ${ }^{1,3,5}$
}

\begin{abstract}
To cite: Wang $\mathrm{H}, \mathrm{He} \mathrm{H,} \mathrm{Yu} \mathrm{Y,}$ et al. Maternal diabetes and the risk of feeding and eating disorders in offspring: a national populationbased cohort study. BMJ Open Diab Res Care 2020;8:e001738. doi:10.1136/ bmjdrc-2020-001738
\end{abstract}

- Supplemental material is published online only. To view, please visit the journal online (http://dx.doi.org/10.1136/ bmjdrc-2020-001738).

Received 28 June 2020 Revised 2 September 2020 Accepted 23 September 2020

Check for updates

\section{(c) Author(s) (or their} employer(s)) 2020. Re-use permitted under CC BY-NC. No commercial re-use. See rights and permissions. Published by BMJ.

For numbered affiliations see end of article.

Correspondence to Dr Jiong Li; j|@clin.au.dk, Dr Hui Wang; whui2015@gmail.com and Professor Fei Li; feili@shsmu.edu.cn

\section{ABSTRACT}

Introduction Previous studies have suggested that maternal diabetes may have programming effect on fetal brain development. However, little is known about the association between maternal diabetes and neurodevelopmental disorders in offspring that mainly manifest in infancy or early childhood. We aimed to examine the association between maternal diabetes before or during pregnancy and feeding and eating disorders (FED) in offspring.

Research design and methods This population-based cohort study included 1193891 singletons born in Denmark during 1996-2015. These children were followed from birth until the onset of FED, the sixth birthday, death, emigration, or 31 December 2016, whichever came first. Relative risk of FED was estimated by HRs using Cox proportional hazards model.

Results A total of 40867 (3.4\%) children were born to mothers with diabetes (20 887 with pregestational diabetes and 19980 with gestational diabetes). The incidence rates of FED were 6.8, 4.6 and 2.9 per 10 000 person-years among children of mothers with pregestational diabetes, gestational diabetes and no diabetes, respectively. Offspring of mothers with diabetes had a $64 \%$ increased risk of FED (HR 1.64; 95\% Cl 1.36 to 1.99; $p<0.001)$. The HR for maternal pregestational diabetes and gestational diabetes was $2.01(95 \% \mathrm{Cl}$ 1.59 to $2.56 ; \mathrm{p}<0.001)$ and $1.28(95 \% \mathrm{Cl} 0.95$ to 1.72 ; $p=0.097)$, respectively. The increased risk was more pronounced among offspring of mothers with diabetic complications (HR 2.97; 95\% Cl 1.54 to 5.72; $p=0.001$ ). Conclusions Maternal diabetes was associated with an increased risk of FED in offspring in infancy and early childhood. Our findings can inform clinical decisions for better management of maternal diabetes, in particular before pregnancy, which can reduce early neurodevelopmental problems in the offspring.

\section{INTRODUCTION}

Feeding and eating disorders (FED) are one of the most common neurodevelopmental disorders during infancy and early childhood, ${ }^{1}$ affecting approximately $0.8 \%-1.4 \%$ of the normally developing children. ${ }^{23}$ FED are characterized by persistent eating disturbances, such as refusal of food and extreme

\section{Significance of this study}

What is already known about this subject?

- The diabetic intrauterine environment can interfere with fetal brain development, which would contribute to an increased susceptibility to neurodevelopmental disorders.

- However, little is known about the association between maternal diabetes during pregnancy and the risk of neurodevelopmental disorders that mainly manifest in infancy or early childhood.

What are the new findings?

- Maternal diabetes before or during pregnancy was associated with an increased risk of feeding and eating disorders in offspring.

- The highest risk of feeding and eating disorders was observed among offspring of mothers with diabetic complications.

\section{How might these results change the focus of} research or clinical practice?

- Early screening and treating diabetes in women during their childbearing age could be important to reduce neurodevelopmental disorders in offspring.

faddiness, and eating-related problems, such as eating of non-edible substances, or voluntary regurgitation of foods after eating in the absence of nausea, involuntary retching, or disgust. ${ }^{4}$ Children with FED often demonstrate lower performances in neuropsychological assessments of executive functioning, visuospatial memory, as well as central coherence. ${ }^{5}$ The etiology of FED is poorly understood, resulting in difficulties in disease prevention and management. ${ }^{6}$

It has been proposed that prenatal risk factors may be involved in the development of FED. ${ }^{17}$ Emerging evidence suggests that adverse intrauterine environment may play a role in the development of neurodevelopmental disorders. ${ }^{89}$ Maternal diabetes during pregnancy may exert long-lasting effects on 
organ development and function in offspring. ${ }^{10} 11$ The diabetic intrauterine environment can interfere with fetal brain development, ${ }^{12}{ }^{13}$ which would contribute to an increased susceptibility to neurodevelopmental disorders. ${ }^{1415}$ Experimental studies have suggested that hyperglycemia during early embryogenesis can disturb neocortical neurogenesis via epigenetic regulations. ${ }^{16} 17$ For example, in a mouse model of a hyperglycemia, it was observed that maternal hyperglycemia could alter histone acetylation and its regulation on the transcription of proneural genes that were associated with disrupted differentiation of neural stem cells and newborn projection neurons in the neocortex. ${ }^{16}$ Epidemiological studies have shown that maternal pregestational type 1 and type 2 diabetes and gestational diabetes mellitus (GDM) are associated with an increased risk of several neurodevelopment disorders in childhood or adolescence, such as autism spectrum disorders (ASD) and attention-deficit/ hyperactivity disorders. ${ }^{15}{ }^{18-20}$ However, little is known about the association between maternal diabetes and the risk of FED that mainly manifests in infancy or early childhood.

We hypothesized that intrauterine exposure to maternal diabetes contributes to an increased risk of FED in offspring. As the odds of neurodevelopment disorders varies by types of maternal diabetes, ${ }^{18} 19$ we conducted a large cohort study to examine the associations between specific types of maternal diabetes and FED in offspring and whether diabetic complications during pregnancy further increased the risk of FED. ${ }^{2122}$

\section{RESEARCH DESIGN AND METHODS}

\section{Data source and cohort identification}

We conducted this secondary analysis of previously collected data of the Danish national registers, such as the Medical Birth Registry, the National Patient Register, the National Prescription Register, and the Psychiatric
Central Research Register. ${ }^{23-27}$ In Denmark, all live births have a unique personal identification number which permits the accurate linkage of individual-level data. We identified all singleton live births from 1 January 1996 to 31 December 2016 ( $\mathrm{n}=1224$ 358) from the Danish Medical Birth Registry, ${ }^{23}$ excluded 26951 children who had missing or extreme gestational age $(<154$ or $>315$ days), 3223 children with chromosomal abnormalities, and 293 children without links to their fathers. The final analysis included 1193891 children (shown in figure 1). We followed each child from birth until the date of the first diagnosis of FED, date of sixth birthday, emigration, death, or end of follow-up (31 December 2016), whichever came first.

\section{Measures}

\section{Maternal diabetes}

Information on maternal diabetes was obtained from the Danish National Patient Register (DNPR) including all inpatient and outpatient records, ${ }^{24}$ the Danish National Diabetes Register, ${ }^{28}$ and the National Prescription Register, ${ }^{27}$ using International Classification of Diseases codes (ICD-8 codes during 1970-1993 and ICD-10 codes since 1994) and Anatomical Therapeutic Chemical (ATC) classification codes. In Denmark, the diagnostic criteria for diabetes are as follows: fasting plasma glucose $\geq 7.0 \mathrm{mmol} / \mathrm{L}$ or 2 -hour postload plasma glucose $\geq 11.1$ $\mathrm{mmol} / \mathrm{L}$ or HBA1c $\geq 6.5 \% .{ }^{29-31}$ According to local screening procedures, GDM was diagnosed ${ }^{32}$ when two or more glucose values exceeded the following capillary whole blood values on oral glucose tolerance test results: $5.7 \mathrm{mmol} / \mathrm{L}$ at $0 \mathrm{~min}, 11.9 \mathrm{mmol} / \mathrm{L}$ at $30 \mathrm{~min}, 12.0$ $\mathrm{mmol} / \mathrm{L}$ at $60 \mathrm{~min}, 9.7 \mathrm{mmol} / \mathrm{L}$ at $90 \mathrm{~min}, 8.9 \mathrm{mmol} / \mathrm{L}$ at $120 \mathrm{~min}, 8.5 \mathrm{mmol} / \mathrm{L}$ at $150 \mathrm{~min}$ and $7.4 \mathrm{mmol} / \mathrm{L}$ at $180 \mathrm{~min}$. Maternal diabetes before childbirth was categorized as pregestational diabetes and gestational diabetes. Pregestational diabetes was ascertained using the

Excluded (n=30 467)

Children with missing or likely errors in gestational age $(n=26951)$

Children who had chromosomal abnormalities

(ICD-10 codes Q90-99) $(n=3223)$

Children with missing links to their fathers $(n=293)$

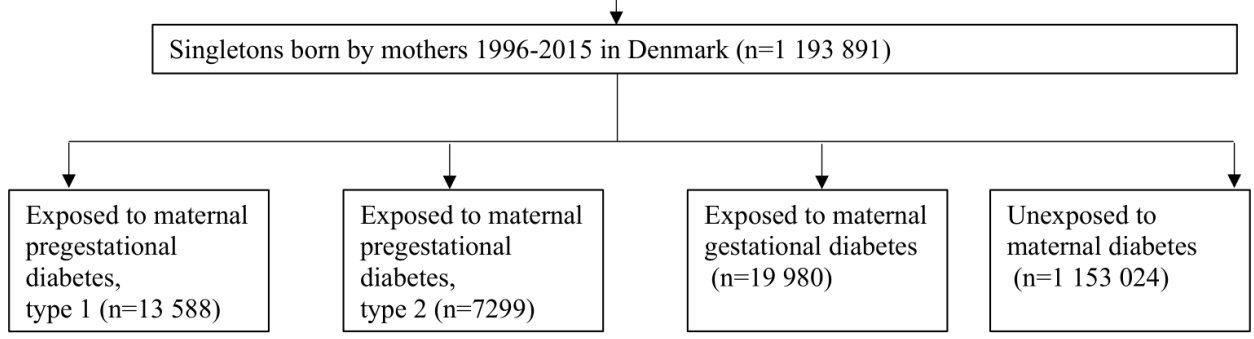

Figure 1 Flow chart showing the identification of the eligible participants and analysis sample. ICD-10, International Classification of Diseases 10th Revision. 
following criteria: (1) diagnosis of diabetes (ICD-8 codes: 249, 250; ICD-10 codes: E10-E11, H36.0, O24 excluding O24.4 and O24.9); (2) receipt of chiropody for patients with diabetes; (3) two redeemed prescriptions for insulin (ATC code: A10A); or (4) two redeemed prescriptions for oral antidiabetics (ATC code: A10B), and type 2 diabetes (ICD-8: 250). ${ }^{22} 33$ Pregestational diabetes was further classified as type 1 diabetes (ICD-8 code: 249; ICD-10 codes: E10, O24.0; ATC codes: A10A) or type 2 diabetes (ICD-8 code: 250; ICD-10 codes: E11, O24.1; ATC code: A10B). ${ }^{22}{ }^{33}$ During 1977-1986 in Denmark, type 1 and type 2 diabetes were recorded using the single ICD-8 code $(250) .{ }^{24}$ We used two approaches to distinguish between type 1 and type 2 diabetes: (1) a specific code for type 1 or type 2 diabetes registered later; or (2) age of diabetes onset (type $1:<30$ years and type $2: \geq 30$ years), as in other studies. ${ }^{21} 2233$

Gestational diabetes has been coded independently throughout the study period (ICD-8: 63474, Y6449; ICD-10: O244, O249). If a mother was recorded with different diabetes types at various hospital contacts, she was classified based on the first diagnosis type. Diabetic complications, such as diabetic coma, ketoacidosis, nephropathy, ophthalmic, neurological, circulatory, and unspecified, or multiple complications, could in part reflect poor glycemic regulation. ${ }^{21}{ }^{22}$ We used DNPR to identify mothers with pregestational diabetes who had diabetic complications (ICD-10 codes: E100-E108, E110E118, and H36.0).

\section{Feeding and eating disorders}

FED, specific to infancy and early childhood, are characterized by refusal of food and extreme faddiness in the presence of an adequate food supply, a reasonably competent caregiver, with the absence of organic disease, and behavioral problems such as eating of non-edible substances (pica) or voluntary regurgitation of foods (rumination-regurgitation disorder). ${ }^{3}$ FED should be diagnosed only if the difficulties are clearly beyond the normal range, if the nature of the eating problem is qualitatively abnormal in character, or if the child fails to gain weight or loses weight over a period of at least 1 month. ${ }^{3}$ Information on FED diagnosed before 6 years old was obtained from the DNPR and the Danish Psychiatric Central Research Register, ${ }^{24}{ }^{25}$ which hold all inpatient and outpatient psychiatric disorders diagnosis in Denmark. The ICD-10 codes for FED were F98.2 and F50.8. ${ }^{1}$

\section{Covariates}

Based on previous research and according to directed acyclic graphs (online supplemental figure 2), ${ }^{11519}$ the following factors were considered as potential confounders and included in the adjusted models: gender of the child (male, female), calendar period of birth (a 5-year interval during 1996-2015), parity (1, 2, $\geq 3)$, maternal age at birth ( $\leq 25,26-30,31-35, \geq 36$ years), paternal age at birth ( $\leq 25,26-30,31-35, \geq 36$ years), maternal country of origin (Denmark, other countries), maternal education level (0-9, 10-14, $\geq 15$ years), maternal cohabitation status (yes, no), maternal smoking status (yes, no), maternal psychiatric disorder history (yes, no), and paternal psychiatric disorder history (yes, no). The information for maternal social status and origin of country was obtained from the Danish Integrated Database for Longitudinal Labor Market Research. ${ }^{34}$

\section{Statistical analysis}

We used Cox proportional hazards regression model to estimate the HR with 95\% CIs for the association of maternal diabetes with the risk of FED in offspring, with offspring's age as the timescale. We categorized mothers with diabetes into four groups: no diabetes, type 1 diabetes, type 2 diabetes and GDM. The mothers with no diabetes were included in the reference group. To control for the correlations of sequential birth of the same mother, the robust sandwich estimator for SE was used. Furthermore, we examined the association between maternal pregestational diabetes and FED in offspring stratified by maternal diabetes complications.

We performed two models for adjusting potential confounders. Model 1 was adjusted for birth of year. Model 2 was additionally adjusted for sex, parity, parental age at birth, maternal education level, maternal origin, maternal cohabitation, maternal smoking during pregnancy, and parental psychiatric disorders before the childbirth.

We performed the causal inference methods for mediation analyses to examine whether adverse birth outcomes (low birth weight, preterm birth, low Apgar score, and small for gestational age) mediated the association between maternal diabetes and FED in offspring by calculating direct and indirect effects (via the mediator) in the STATA module PARAMED. ${ }^{35}$ The proportion of mediation was calculated as $\log$ (natural indirect relationship)/log (total relationship).

We did several sensitivity analyses. First, in order to examine the potential mediating effects of preterm birth, we repeated the analyses only including term-born children ( $\geq 37$ gestational weeks) to see whether the associations would be changed significantly, compared with those overall estimates. Second, we also examined the paternal diabetes as the exposure to explore the potential roles of genetic components and family environmental factors. Paternal diabetes was identified with the same strategy as for maternal diabetes. Additionally, we also conducted cosibling analyses to explore potential confounding by shared familial factors (genetic and/ or environmental). ${ }^{36}$ Third, as maternal pregnancy body mass index became available since 2004, we restricted the analysis to offspring born afterward. Fourth, we repeated our analysis by excluding children born with cleft lip and cleft palate (Q35-Q37), and other congenital malformations of the digestive system (Q38-Q45). Fifth, we also conducted analyses by extracting information on maternal diabetes through patient registers only 
rather than combination of hospitalization registers and prescription data. Finally, we examined potential sexspecific associations between maternal diabetes and FED in offspring by including an interaction term between sex of the child and maternal diabetes. All statistical analyses were performed with Stata V.15.

\section{RESULTS}

Of the 1193891 singleton live-born offspring, 20887 $(1.7 \%)$ were exposed to maternal pregestational diabetes (type 1: $1.1 \%$, type 2: $0.6 \%$ ) and $19980(1.7 \%)$ were exposed to gestational diabetes. The proportion of offspring exposed to maternal diabetes increased with the year of birth (online supplemental figure 1). Table 1 shows the characteristics of mothers and children in the exposed and unexposed groups. Compared with unexposed offspring, exposed offspring were more likely to be born preterm. Compared with mothers without diabetes, mothers with diabetes were on average older, more likely to have higher parity, to live alone, and be non-smokers during pregnancy. Mothers with diabetes also had a higher prevalence of psychiatric disorders.

A total of $2099(0.2 \%)$ offspring were diagnosed with FED with a mean age at diagnosis of 1.2 years. Offspring of women with diabetes were 1.64 times (HR 1.64; $95 \%$ CI 1.36 to $1.99 ; \mathrm{p}<0.001)$ more likely to have FED than the offspring of mothers without diabetes (incidence rate of FED 0.57 per 1000 person-years vs 0.29 per 1000 personyears). For example, the rate of 0.57 per 1000 personyears could be considered that when we follow 100000 children for 1 year, 57 of them will develop FED. The magnitude of association was higher in offspring exposed to maternal pregestational diabetes (HR 2.01; $95 \%$ CI 1.59 to $2.56 ; \mathrm{p}<0.001)$ than in those exposed to gestational diabetes (HR 1.28; 95\% CI 0.95 to $1.72 ; \mathrm{p}=0.097$ ). Both maternal pregestational type 1 diabetes (HR 1.73; 95\% CI 1.26 to 2.38; $\mathrm{p}=0.001$ ) and type 2 diabetes (HR 2.53 ; $95 \%$ CI 1.78 to $3.59 ; \mathrm{p}<0.001)$ were associated with an increased risk of FED in offspring (table 2).

Among women with pregestational diabetes, $16.6 \%$ had pregestational diabetic complications. The risk of FED in offspring of mothers with pregestational diabetes and diabetic complications was 2.97-fold (HR 2.97; 95\% CI 1.54 to $5.72 ; \mathrm{p}=0.001$ ) than those of mothers with pregestational diabetes but without diabetic complications (HR 1.92; $95 \%$ CI 1.49 to 2.48 ; $\mathrm{p}<0.001$ ) (table 3 ).

Adverse birth outcomes accounted for a very small proportion of the association between maternal diabetes and risk of FED, although almost all the natural indirect association estimates were marginally statistically significant (table 4).

When excluding offspring with preterm birth, the estimates remained unchanged (online supplemental table 1). No association was observed for paternal diabetes and FED risk in offspring (online supplemental table 2). In the cosibling analyses, similar association was yielded (online supplemental table 3). Results from the analyses restricted to offspring born after 2004 or excluding children born with cleft lip and cleft palate, and other congenital malformations of the digestive system were consistent (online supplemental tables 4 and 5). Stratification for sex of the offspring did not show any significant differences in estimates from the main analyses (online supplemental table 6). When obtaining information on maternal diabetes only from patient registers, results were similar (online supplemental table 7).

\section{DISCUSSION}

In this large cohort study, we found that maternal diabetes before or during pregnancy was associated with an increased risk of FED in offspring. Children of mothers with pregestational diabetes (type 1 or type 2 diabetes) had varied increased risks (1.73 for type 1; 2.53 for type 2) than those of mothers without diabetes, which were higher than that in children of mothers with GDM only. The highest risk of FED was observed among offspring of mothers with diabetic complications. Mediation analyses further indicated that adverse birth outcomes could only explain a very small proportion of the overall effects.

Our findings are, in general, consistent with previous studies on the association between maternal pregestational diabetes and neurodevelopmental disorders in childhood or adolescence, ${ }^{14} 1518-203738$ but it is new to observe the elevated risk in infancy and early childhood. We further observed that the associations of type 1 and type 2 diabetes with FED might vary in magnitude. The variations in the magnitude of the FED risk in offspring by subtypes of maternal diabetes could be due to the different pathophysiological mechanisms underlying subtypes of diabetes, ${ }^{39}$ which warrants further investigations.

Regarding GDM, a meta-analysis of both prospective and cross-sectional studies reported that GDM was associated with ASD in offspring. ${ }^{40}$ However, a large population-based study in the USA found that only GDM diagnosed before 26 weeks was significantly associated with risk for ASD. ${ }^{19}$ Our stratified analyses found that children exposed to GDM diagnosed before 26 weeks had a similar HR, compared with children exposed to GDM at any time. Several register-based studies have suggested that the association between GDM and neurodevelopmental disorders in offspring was only observed in children of parents with lower socioeconomic position or of mothers with obesity. ${ }^{14} 18$ 41-43 These discrepancies might be explained by different screening procedures, diagnostic criteria, and treatment guidelines for GDM, or measurements for offspring neurodevelopment. ${ }^{40}$

Potential biological mechanisms linking maternal diabetes during pregnancy and FED risk in offspring may involve multiple pathways. During diabetic pregnancies, maternal hyperglycemia may predispose fetuses to a proinflammatory state with fetal hyperinsulinemia,${ }^{44}$ increased oxidative stress, ${ }^{45}$ chronic inflammation, ${ }^{11}$ and hypoxia, ${ }^{46}$ which in turn could interfere with brain development 
Table 1 Characteristics of the study population born between 1996 and 2015 at birth according to maternal diabetes status

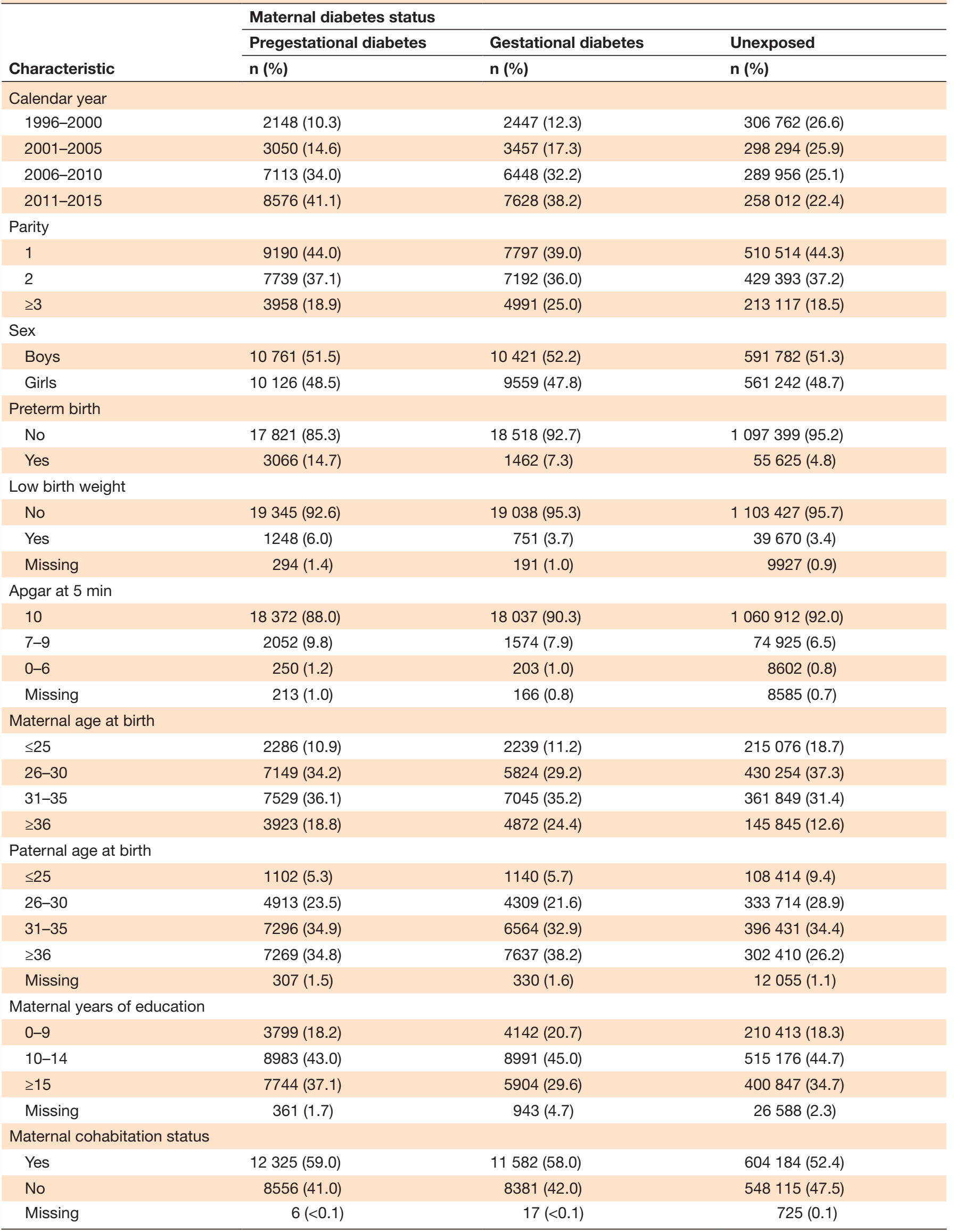

Continued 
Table 1 Continued

\begin{tabular}{lccc}
\hline & \multicolumn{2}{c}{ Maternal diabetes status } & \\
\cline { 2 - 4 } Characteristic & Pregestational diabetes & Gestational diabetes & Unexposed \\
\cline { 2 - 4 } & $\mathbf{n}(\%)$ & $\mathbf{n}(\%)$ & $\mathbf{n}(\%)$ \\
\hline Maternal origin & & \\
\hline Born in Denmark & $17800(85.2)$ & $14937(74.8)$ & $984608(85.4)$ \\
\hline Not born in Denmark & $3083(14.8)$ & $5036(25.2)$ & $168064(14.6)$ \\
\hline Missing & $4(<0.1)$ & $7(<0.1)$ & $352(<0.1)$ \\
\hline Maternal psychiatric disorders & & & $99820(8.7)$ \\
\hline Yes & $2983(14.3)$ & $2457(12.3)$ & $1053204(91.3)$ \\
\hline No & $17904(85.7)$ & $17523(87.7)$ & $196070(17.0)$ \\
\hline Maternal smoking status during pregnancy & & $926720(80.4)$ \\
\hline Yes & $2924(14.0)$ & $3130(15.1)$ & $30234(2.6)$ \\
\hline No & $17167(82.2)$ & $642(3.2)$ & \\
\hline Missing & $796(3.8)$ & & \\
\hline
\end{tabular}

during the critical period and lead to subsequently neurobehavioral disorders in later life. ${ }^{1247}$ Previous studies have established that the development of neurons and brain circuits, that is, proliferation, migration, differentiation, is an array of complex processes, and are more susceptible to environmental insults during early pregnancy. ${ }^{48}$ During this period, maternal hyperglycemia may play a more critical role in the etiology of neurodevelopment disorders. ${ }^{5051}$ Maternal hyperglycemia has also been associated with epigenetic modifications which potentially mediate the link between maternal diabetes and FED risk in offspring. ${ }^{52}$ Experimental studies in rats have suggested that epigenetic modifications of neocortical neurogenesis due to alterations in the hyperglycemic intrauterine environment increased the susceptibility to neurodevelopment disorders in later life. ${ }^{16}$ In addition, infants born to mother with diabetes have higher serum leptin and Mendelian randomization supports the causal relationship between maternal hyperglycemia and epigenetic regulation of leptin gene in newborns. ${ }^{53}$ Leptin, one of the anorexigenic neurotransmitters, may restrain the feeding behavior by restricting the availability or counteracting the orexigenic effect of neuropeptide $\mathrm{Y}^{54}$ which may partly explain the disturbed feeding behaviors in offspring of mothers with diabetes.

It is noteworthy that children of mothers with diabetic complications have the highest risk of FED. Diabetic complications are closely correlated with insulin resistance and may reflect the severity of pregestational diabetes and poor glycemic control. ${ }^{55}$ Similarly, previous studies have found a higher risk of genital anomalies and cardiovascular diseases in offspring of mothers with diabetic complications. ${ }^{21} 33$ Maternal poor glycemic control in pregnancy may exert potential implications in offspring for behavioral and emotional problems. ${ }^{5657}$

\section{Strengths and limitations of this study}

This study has several strengths. First, methodological strengths of this study include its use of the Danish register data, which provide a large and representative sample with more than 1 million children. Second, in this study, we have used Cox proportional hazards model. This statistical model can take into consideration of time until FED occur and compare the incidence rate of events over time for different groups, while adjusting for various potential confounders. Third, the data used in

Table 2 Association between maternal diabetes and risk of feeding and eating disorders in offspring

\begin{tabular}{|c|c|c|c|c|c|}
\hline Exposure & $\begin{array}{l}\text { Cases } \\
\text { (n) }\end{array}$ & $\begin{array}{l}\text { Rate per } 1000 \\
\text { person-years }\end{array}$ & $\begin{array}{l}\text { HR }(95 \% \text { Cl) } \\
\text { Model } 1\end{array}$ & $\begin{array}{l}\text { HR }(95 \% \text { Cl) } \\
\text { Model } 2\end{array}$ & $P$ value \\
\hline No diabetes & 1966 & 0.29 & Ref 1.00 & Ref 1.00 & \\
\hline Maternal diabetes & 133 & 0.57 & 1.81 (1.52 to 2.16$)$ & 1.64 (1.36 to 1.99$)$ & $<0.001$ \\
\hline Pregestational diabetes & 79 & 0.68 & 2.15 (1.71 to 2.69$)$ & 2.01 (1.59 to 2.56 ) & $<0.001$ \\
\hline Type 1 diabetes & 44 & 0.59 & 1.85 (1.37 to 2.50$)$ & 1.73 (1.26 to 2.38$)$ & 0.001 \\
\hline Type 2 diabetes & 35 & 0.84 & 2.68 (1.92 to 3.74$)$ & 2.53 (1.78 to 3.59$)$ & $<0.001$ \\
\hline Gestational diabetes & 54 & 0.46 & 1.47 (1.12 to 1.93$)$ & 1.28 (0.95 to 1.72$)$ & 0.097 \\
\hline
\end{tabular}

Model 1 adjusted for birth year; model 2 additionally adjusted for parity, maternal characteristics (age, education level, origin, cohabitation, smoking status during pregnancy, psychiatric disorder history) and paternal age. 
Table 3 Association between maternal diabetic complications and risk of feeding and eating disorders during 1996-2015

\begin{tabular}{|c|c|c|c|c|c|}
\hline Exposure & Cases (n) & $\begin{array}{l}\text { Rate per } 1000 \\
\text { person-years }\end{array}$ & $\begin{array}{l}\text { HR }(95 \% \mathrm{Cl}) \\
\text { Model } 1\end{array}$ & $\begin{array}{l}\text { HR }(95 \% \mathrm{Cl}) \\
\text { Model } 2\end{array}$ & P value \\
\hline No pregestational diabetes & 1966 & 0.29 & Ref 1.00 & Ref 1.00 & \\
\hline $\begin{array}{l}\text { Pregestational diabetes without } \\
\text { complications }\end{array}$ & 69 & 0.65 & 2.04 (1.60 to 2.60$)$ & 1.92 (1.49 to 2.48$)$ & $<0.001$ \\
\hline $\begin{array}{l}\text { Pregestational diabetes with } \\
\text { complications }\end{array}$ & 10 & 0.99 & $3.30(1.77$ to 6.14$)$ & 2.97 (1.54 to 5.72$)$ & 0.001 \\
\hline
\end{tabular}

Model 1 adjusted for birth year; model 2 additionally adjusted for parity, maternal characteristics (age, education level, origin, cohabitation, smoking status during pregnancy, psychiatric disorder history) and paternal age.

this study were extracted from national registers which have been proved to be reliable and of high quality. ${ }^{24} 2528$ Furthermore, the data are prospectively collected, so the possibility of recall bias could be ruled out.

Our study also had several limitations. First, the FED treated in private clinics could not be included. However, misclassification of FED might be expected to be nondifferential by maternal diabetes and therefore are more likely to influence our results toward the null. Second, the potential misclassification bias might also remain for maternal diabetes. Before 1986, type 1 and type 2 diabetes were recorded using the same ICD- 8 codes. ${ }^{28}$ We further validated the diagnosis by using the specific register information for diabetes later and previous studies have indicated the high validity of Danish diabetic diagnosis in epidemiological studies. Third, although we adjusted for relevant confounders, as in other observational studies, we cannot completely rule out the possibility of residual

Table 4 Mediation analysis with adverse birth outcomes as potential mediators between maternal diabetes and risk of feeding and eating disorders in offspring

\begin{tabular}{ll}
\hline Variables & OR (95\% Cl)* \\
\hline Low birth weight & \\
\hline Natural direct effect & $1.55(1.25$ to 1.83$)$ \\
\hline Natural indirect effect & $1.03(1.02$ to 1.04$)$ \\
\hline Total effect & $1.60(1.29$ to 1.88$)$ \\
\hline Proportion (\%) $\dagger$ & 6.29 \\
\hline Preterm birth & \\
\hline Natural direct effect & $1.49(1.20$ to 1.75$)$ \\
\hline Natural indirect effect & $1.09(1.07$ to 1.11$)$ \\
\hline Total effect & $1.62(1.30$ to 1.91$)$ \\
\hline Proportion (\%) & 17.86 \\
\hline Low Apgar score & \\
\hline Natural direct effect & $1.61(1.30$ to 1.90$)$ \\
\hline Natural indirect effect & $1.00(1.00$ to 1.01$)$ \\
\hline Total effect & $1.62(1.31$ to 1.91$)$ \\
\hline Proportion (\%) & 0.99 \\
\hline
\end{tabular}

*Adjusted for sex, birth year, parity, parental age, maternal smoking during pregnancy, maternal education level, maternal country of origin, maternal cohabitation and maternal psychiatric disorders. †Proportion mediated was calculated as log (natural indirect relationship)/log (total relationship). confounding by unmeasured confounders. However, the cosibling analyses showed that they were not explained by unmeasured shared familial factors. In addition, no significant association between paternal diabetes further suggested the findings are unlikely to be explained by the uncontrolled confounding completely. Lastly, pregestational diabetes with complications could indicate severity of diabetes, poor glycemic control or duration of exposure to hyperglycemia. However, due to lack of detailed information on these factors, we could not explore further on this issue and further research is warranted.

\section{CONCLUSION}

Maternal diabetes was associated with an increased risk of FED in offspring in infancy and early childhood. Our findings highlight the importance of better management of maternal diabetes, which may contribute to reduce the incidence of neurodevelopmental problems in the offspring like FED.

\section{Author affiliations}

${ }^{1}$ MOE-Shanghai Key Laboratory of Children's Environmental Health, Xinhua Hospital Affiliated to Shanghai Jiao Tong University School of Medicine, Shanghai, China ${ }^{2}$ Developmental and Behavioural Pediatric Department \& Child Primary Care Department, Xinhua Hospital Affiliated to Shanghai Jiao Tong University School of Medicine, Shanghai, China

${ }^{3}$ Department of Clinical Epidemiology, Aarhus University, Aarhus, Denmark ${ }^{4}$ Clinical Research Center, Shanghai First Maternity and Infant Hospital Affiliated to Tongji University, Shanghai, China

${ }^{5}$ School of Global Health, Chinese Center for Tropical Disease Research, Shanghai Jiao Tong University School of Medicine, Shanghai, China

Contributors HW preformed the literature review, conducted data analyses and drafted the manuscript. $\mathrm{HH}, \mathrm{YY}$, and XS contributed to the interpretation of the data, critical revision of the paper and approval of the final version. HW, FL and JL are the guarantors of the study. They developed the study conception, directed the analytic strategy of the study and supervised the drafting of the manuscript. All authors approved the final manuscript as submitted and agreed to be accountable for all aspects of the work

Funding This study was funded by the National Nature Science Foundation of China (№ 81703237, № 81930095, № 81761128035, № 81701334, № 81703249), the Shanghai Municipal Commission of Health and Family Planning (No 2017ZZO2026, No 2018BR33, No 2017EKHWYX-02), the Shanghai Shenkang Hospital Development Center (No 16CR2025B), the Shanghai Clinical Key Subject Construction Project (shslczdzk02902), the Shanghai Committee of Science and Technology (No 17XD1403200, No 19410713500, No 18DZ2313505), the Shanghai Municipal Science and Technology Major Project (No 2018SHZDZX01), the Key Scientific and Technological Projects of Guangdong Province (2018B030335001), the Collaborative Innovation Program of Shanghai Municipal Health Commission (2020CXJQ01), the National Human Genetic Resources Sharing Service Platform 
(2005DKA21300), the Xinhua Hospital of Shanghai Jiao Tong University School of Medicine (2018YJRC03), the Novo Nordisk Foundation (NNF180C0052029), the Danish Council for Independent Research (DFF-6110-00019B and 9039-00010B), the Nordic Cancer Union (176673, 186200, and R217-A13234-18-S65), and the Karen Elise Jensens Fond (2016).

Competing interests None declared.

Patient consent for publication Not required.

Ethics approval The study was approved by the Danish Data Protection Agency (No 2013-41-2569) and the Danish Health Data Authority.

Provenance and peer review Not commissioned; externally peer reviewed.

Data availability statement № data are available. Data are not publicly available.

Supplemental material This content has been supplied by the author(s). It has not been vetted by BMJ Publishing Group Limited (BMJ) and may not have been peer-reviewed. Any opinions or recommendations discussed are solely those of the author(s) and are not endorsed by BMJ. BMJ disclaims all liability and responsibility arising from any reliance placed on the content. Where the content includes any translated material, BMJ does not warrant the accuracy and reliability of the translations (including but not limited to local regulations, clinical guidelines, terminology, drug names and drug dosages), and is not responsible for any error and/or omissions arising from translation and adaptation or otherwise.

Open access This is an open access article distributed in accordance with the Creative Commons Attribution Non Commercial (CC BY-NC 4.0) license, which permits others to distribute, remix, adapt, build upon this work non-commercially, and license their derivative works on different terms, provided the original work is properly cited, appropriate credit is given, any changes made indicated, and the use is non-commercial. See: http://creativecommons.org/licenses/by-nc/4.0/.

ORCID iD

Jiong Li http://orcid.org/0000-0003-1125-026X

\section{REFERENCES}

1 Hvelplund C, Hansen BM, Koch SV, et al. Perinatal risk factors for feeding and eating disorders in children aged 0 to 3 years. Pediatrics 2016;137:e20152575

2 Su X, Xu B, Liang H, et al. Prenatal maternal bereavement and risk of eating disorders in infants and toddlers: a population-based cohort study. BMC Psychiatry 2015;15:229.

3 Nicholls D, Bryant-Waugh R. Eating disorders of infancy and childhood: definition, symptomatology, epidemiology, and comorbidity. Child Adolesc Psychiatr Clin N Am 2009;18:17-30.

4 Treasure J, Duarte TA, Schmidt U. Eating disorders. Lancet 2020;395:899-911.

5 Rose M, Frampton I, Lask B. A case series investigating distinct neuropsychological profiles in children and adolescents with anorexia nervosa. Eur Eat Disord Rev 2012;20:32-8.

6 Bryant-Waugh R, Markham L, Kreipe RE, et al. Feeding and eating disorders in childhood. Int J Eat Disord 2010;43:NA-111.

7 Zhang T, Sidorchuk A, Sevilla-Cermeño L, et al. Association of cesarean delivery with risk of neurodevelopmental and psychiatric disorders in the offspring: a systematic review and meta-analysis. JAMA Netw Open 2019;2:e1910236-e36.

8 MacKinnon N, Kingsbury M, Mahedy L, et al. The association between prenatal stress and externalizing symptoms in childhood: evidence from the avon longitudinal study of parents and children. Biol Psychiatry 2018;83:100-8.

9 O'Donnell KJ, Meaney MJ. Fetal origins of mental health: the developmental origins of health and disease hypothesis. $A m \mathrm{~J}$ Psychiatry 2017;174:319-28.

10 Cross JA, Temple RC, Hughes JC, et al. Cord blood telomere length, telomerase activity and inflammatory markers in pregnancies in women with diabetes or gestational diabetes. Diabet Med 2010;27:1264-70

11 Thakali KM, Saben J, Faske JB, et al. Maternal pregravid obesity changes gene expression profiles toward greater inflammation and reduced insulin sensitivity in umbilical cord. Pediatr Res 2014:76:202-10.

12 Money KM, Barke TL, Serezani A, et al. Gestational diabetes exacerbates maternal immune activation effects in the developing brain. Mol Psychiatry 2018;23:1920-8.

13 Schleger F, Linder K, Walter L, et al. Family history of diabetes is associated with delayed fetal postprandial brain activity. Front Endocrinol 2018;9:673.
14 Daraki V, Roumeliotaki T, Koutra K, et al. Effect of parental obesity and gestational diabetes on child neuropsychological and behaviora development at 4 years of age: the Rhea mother-child cohort, Crete, Greece. Eur Child Adolesc Psychiatry 2017;26:703-14.

15 Kong L, Norstedt G, Schalling M, et al. The risk of offspring psychiatric disorders in the setting of maternal obesity and diabetes. Pediatrics 2018;142:e20180776.

16 Ji S, Zhou W, Li X, et al. Maternal hyperglycemia disturbs neocortical neurogenesis via epigenetic regulation in C57BL/6J mice. Cell Death Dis 2019:10:1-13.

17 Banik A, Kandilya D, Ramya S, et al. Maternal factors that induce epigenetic changes contribute to neurological disorders in offspring. Genes 2017;8:150.

18 Xiang AH, Wang X, Martinez MP, et al. Maternal gestational diabetes mellitus, type 1 diabetes, and type 2 diabetes during pregnancy and risk of ADHD in offspring. Diabetes Care 2018;41:2502-8.

19 Xiang AH, Wang X, Martinez MP, et al. Association of maternal diabetes with autism in offspring. JAMA 2015;313:1425-34.

20 Kong L, Nilsson IAK, Brismar K, et al. Associations of different types of maternal diabetes and body mass index with offspring psychiatric disorders. JAMA Netw Open 2020;3:e1920787-e87.

21 Øyen N, Diaz LJ, Leirgul E, et al. Prepregnancy diabetes and offspring risk of congenital heart disease: a nationwide cohort study. Circulation 2016;133:2243-53

22 Yu Y, Arah OA, Liew Z, et al. Maternal diabetes during pregnancy and early onset of cardiovascular disease in offspring: population based cohort study with 40 years of follow-up. BMJ 2019;367:16398.

23 Bliddal M, Broe A, Pottegård A, et al. The Danish medical birth register. Eur J Epidemiol 2018;33:27-36.

24 Lynge E, Sandegaard JL, Rebolj M. The Danish national patient register. Scand J Public Health 2011;39:30-3.

25 Mors O, Perto GP, Mortensen PB. The Danish psychiatric central research register. Scand J Public Health 2011;39:54-7.

26 Schmidt M, Schmidt SAJ, Sandegaard JL, et al. The Danish national patient registry: a review of content, data quality, and research potential. Clin Epidemiol 2015;7:449.

27 Kildemoes HW, Sørensen HT, Hallas J, Wallach Kildemoes H, Toft Sørensen $\mathrm{H}$. The Danish national prescription registry. Scand $\mathrm{J}$ Public Health 2011;39:38-41.

28 Green A, Sortsø C, Jensen PB, et al. Validation of the Danish national diabetes register. Clin Epidemiol 2015;7:5.

29 Carstensen B, Kristensen JK, Ottosen P, et al. The Danish national diabetes register: trends in incidence, prevalence and mortality. Diabetologia 2008;51:2187-96.

30 Carstensen B, Kristensen JK, Marcussen MM, et al. The National diabetes register. Scand J Public Health 2011;39:58-61.

31 Glümer C, Jørgensen T, Borch-Johnsen K, et al. Prevalences of diabetes and impaired glucose regulation in a Danish population: the Inter99 study. Diabetes Care 2003;26:2335-40.

32 Olsen SF, Houshmand-Oeregaard A, Granström C, et al. Diagnosing gestational diabetes mellitus in the Danish national birth cohort. Acta Obstet Gynecol Scand 2017:96:563-9.

33 Arendt LH, Lindhard MS, Henriksen TB, et al. Maternal diabetes mellitus and genital anomalies in male offspring. Epidemiology 2018;29:280-9.

34 Petersson F, Baadsgaard M, Thygesen LC. Danish registers on personal labour market affiliation. Scand $J$ Public Health 2011;39:95-8.

35 Emsley R, Liu H. PARAMED: stata module to perform causal mediation analysis using parametric regression models, 2013 Available: https://econpapers.repec.org/software/bocbocode/ s457581.htm [Accessed 01 Nov 2018].

36 Crump C, Howell EA, Stroustrup A, et al. Association of preterm birth with risk of ischemic heart disease in adulthood. JAMA Pediatr 2019:173:736-43.

37 Li M, Fallin MD, Riley A, et al. The association of maternal obesity and diabetes with autism and other developmental disabilities. Pediatrics 2016;137:e20152206.

$38 \mathrm{Ji}$ J, Chen T, Sundquist J, et al. Type 1 diabetes in parents and risk of attention deficit/hyperactivity disorder in offspring: a populationbased study in Sweden. Diabetes Care 2018;41:770-4.

39 Huynh J, Yamada J, Beauharnais C, et al. Type 1, type 2 and gestational diabetes mellitus differentially impact placental pathologic characteristics of uteroplacental malperfusion. Placenta 2015;36:1161-6.

40 Xu G, Jing J, Bowers K, et al. Maternal diabetes and the risk of autism spectrum disorders in the offspring: a systematic review and meta-analysis. J Autism Dev Disord 2014:44:766-75.

41 Nomura Y, Marks DJ, Grossman B, et al. Exposure to gestational diabetes mellitus and low socioeconomic status: effects on neurocognitive development and risk of attention-deficit/ 
hyperactivity disorder in offspring. Arch Pediatr Adolesc Med 2012;166:337-43.

42 Schmitt J, Romanos M. Prenatal and perinatal risk factors for attention-deficit/hyperactivity disorder. Arch Pediatr Adolesc Med 2012;166:1074-5.

43 Dodds L, Fell DB, Shea S, et al. The role of prenatal, obstetric and neonatal factors in the development of autism. J Autism Dev Disord 2011;41:891-902.

44 Westgate JA, Lindsay RS, Beattie J, et al. Hyperinsulinemia in cord blood in mothers with type 2 diabetes and gestational diabetes mellitus in New Zealand. Diabetes Care 2006;29:1345-50.

45 Wang X, Lu J, Xie W, et al. Maternal diabetes induces autism-like behavior by hyperglycemia-mediated persistent oxidative stress and suppression of superoxide dismutase 2. Proc Natl Acad Sci U S A 2019;116:23743-52.

46 Teramo K, Piñeiro-Ramos JD. Fetal chronic hypoxia and oxidative stress in diabetic pregnancy. could fetal erythropoietin improve offspring outcomes? Free Radic Biol Med 2019;142:32-7.

47 Meyer U. Neurodevelopmental resilience and susceptibility to maternal immune activation. Trends Neurosci 2019;42:793-806.

48 Thompson BL, Levitt P, Stanwood GD. Prenatal exposure to drugs: effects on brain development and implications for policy and education. Nat Rev Neurosci 2009;10:303-12.

49 Torii M, Sasaki M, Chang Y-W, et al. Detection of vulnerable neurons damaged by environmental insults in utero. Proc Natl Acad Sci U S A 2017;114:2367-72.
50 Guzzardi MA, Sanguinetti E, Bartoli A, et al. Elevated glycemia and brain glucose utilization predict BDNF lowering since early life. $J$ Cereb Blood Flow Metab 2018;38:447-55.

51 Meek TH, Wisse BE, Thaler JP, et al. Bdnf action in the brain attenuates diabetic hyperglycemia via insulin-independent inhibition of hepatic glucose production. Diabetes 2013;62:1512-8.

52 Hjort L, Novakovic B, Grunnet LG, et al. Diabetes in pregnancy and epigenetic mechanisms-how the first 9 months from conception might affect the child's epigenome and later risk of disease. Lancet Diabetes Endocrinol 2019;7:796-806.

53 Allard C, Desgagné V, Patenaude J, et al. Mendelian randomization supports causality between maternal hyperglycemia and epigenetic regulation of leptin gene in newborns. Epigenetics 2015;10:342-51.

54 Singh BS, Westfall TC, Devaskar SU. Maternal diabetes-induced hyperglycemia and acute intracerebral hyperinsulinism suppress fetal brain neuropeptide $Y$ concentrations. Endocrinology 1997;138:963-9.

$55 \mathrm{Xu} \mathrm{H}, \mathrm{Du} \mathrm{X}, \mathrm{Xu}$ J, et al. Pancreatic $\beta$ cell microRNA-26a alleviates type 2 diabetes by improving peripheral insulin sensitivity and preserving $\beta$ cell function. PLoS Biol 2020;18:e3000603.

56 Catalano PM, McIntyre HD, Cruickshank JK, et al. The hyperglycemia and adverse pregnancy outcome study: associations of GDM and obesity with pregnancy outcomes. Diabetes Care 2012;35:780-6.

57 Gray SG, Sweeting AN, Mcguire TM, et al. Changing environment of hyperglycemia in pregnancy: gestational diabetes and diabetes mellitus in pregnancy. J Diabetes 2018;10:633-40. 